\title{
Hydrogen interaction in ultrafine grain duplex stainless steel 2205 aged after cold rolling
}

\author{
Loyslene Rabelo Fernandes ${ }^{1}$ \\ Thais Braga de Abreu \\ Lisa Claeys ${ }^{2}$ \\ Tom Depover ${ }^{2}$ \\ Kim Verbeken ${ }^{2}$ \\ Dagoberto Brandão Santos ${ }^{1 *}$ (1)
}

\begin{abstract}
Duplex stainless steels (DSS) have a microstructure of ferrite and austenite. These alloys have a high strength combined with ductility and good corrosion resistance. They are widely used in the petrochemical, paper and nuclear industries. However, like other stainless steels, they are susceptible to hydrogen embrittlement (HE). DSS 2205 samples were received under the condition of homogenization annealing $\left(1050^{\circ} \mathrm{C}\right.$ for $300 \mathrm{~s}$ and cooling in water). Then, they were cold rolled to $60 \%$ thickness reduction and annealed at $1100^{\circ} \mathrm{C}$ for $7200 \mathrm{~s}$ and aged at $850^{\circ} \mathrm{C}$ for $86400 \mathrm{~s}$, then charged with hydrogen. Melt extraction analyzes were applied to quantify the hydrogen in the steel. In situ tensile tests, with simultaneous hydrogen charging, were used to assess the embrittlement caused by this element. Completing the hydrogen analyzes, thermal desorption spectra (TDS) were constructed. In the aged condition, the phases ferrite, austenite, sigma $(\sigma)$, chi $(\chi)$ and carbide $\left(\mathrm{M}_{23} \mathrm{C}_{6}\right)$ were identified. The DSS showed a considerable reduction in ductility, reaching $5 \%$ total elongation in the aged state. Hydrogen charging did not change this condition. Melt extraction revealed a hydrogen content in the microstructure of up to $50 \mathrm{wppm}$ for the annealed condition, while for the aged sample it was $10 \mathrm{wppm}$.
\end{abstract}

Keywords: Duplex stainless steel; Hydrogen embrittlement; Hydrogen absorption; Hydrogen diffusivity; Brittle fracture.

\section{Introduction}

The DSS are part of a class of materials with dual phase microstructure, consisting of alternating lamellae of ferrite and austenite, possessing approximately equal volume fraction, $50 \%$ for each phase [1-3]. The presence of both phases provides a good balance between mechanical properties and corrosion resistance, making stainless steel of great importance for its application, being used increasingly in harsh environments such as nuclear power plants, chemical, petrochemical, and paper industries [2-4].

Generally, these steels when subjected to deformation can suffer a strain induced phase transformation, the austenite transforms to martensite. The formation of martensite is associated with the stability of the austenite, where it is related to the stacking fault energy (SFE), dependent on the alloy composition and temperature $[5,6]$. When the DSS is exposed to temperatures varying from 600 to $1000^{\circ} \mathrm{C}$, deleterious phases may precipitate, such as intermetallic phases, carbides and nitrides [7]. These phases present high precipitation kinetics, resulting in severe deterioration of ductility, an increase of strength and loss of corrosion resistance [8-10] of these steels; which is caused by the depletion of $\mathrm{Cr}$ and $\mathrm{Mo}$ in the matrix and its accumulation in the secondary phases $[9,10]$.

Because the stainless steel has become of great interest to the market, it becomes important to know its mechanical behavior and corrosion resistance when combined with hydrogen. Mechanical efforts and aggressive environments can lead to embrittlement of the DSS when charged with hydrogen. The analysis of the susceptibility to hydrogen embrittlement in stainless steel is complex, due to its nature of multi microconstituents, besides both phases behave in a non-similar way concerning to hydrogenrelated performance. The ferrite shows a low solubility and diffusivity of hydrogen, while the austenite shows high solubilization and low diffusivity of this element [11-13]. Present in the microstructure of steel, hydrogen leads to a reduction in its toughness and ductility, and, in many cases, is related to the tensile strength of steel, that is, the greater its strength, more susceptible to hydrogen embrittlement phenomena [11-14]. The interaction of

${ }^{\prime}$ Departamento de Engenharia de Metalúrgica e de Materiais, Universidade Federal de Minas Gerais - UFMG, Campus Pampulha, Belo Horizonte, MG, Brasil.

${ }^{2}$ Department of Materials, Textiles and Chemical Engineering, Ghent University, Tech Lane Ghent Science Park Campus A, Zwijnaarde, Belgium.

*Corresponding author:dsantos@demet.ufmg.br

2176-1523 C 2021. Fernandes et al. Published by ABM. This is an Open Access article distributed under the terms of the Creative Commons Attribution License, which permits unrestricted use, distribution, and reproduction in any medium, provided the original work is properly cited. 
hydrogen with steels with bcc crystalline structure has already been observed, showing that the role of diffused hydrogen was essential for the degree of embrittlement. Despite the quantity, hydrogen diffusivity also plays an important role. Therefore, fcc materials that have a low hydrogen content, with low diffusivity properties, were considered resistant to hydrogen embrittlement. This undesirable phenomenon can ultimately have an unfavorable effect on mechanical properties, with very harmful consequences due to exposure to an environment containing hydrogen [14-17].

This work deals with the determination of certain particularities of the effects of hydrogen on an aged DSS after cold rolling. It was investigated the amount of hydrogen present and its trapping in the material, the degradation of its mechanical properties caused by aging with the formation of deleterious phases, as well as the simultaneous charging with hydrogen. The motivation for this work comes from the susceptibility to hydrogen embrittlement in duplex stainless steels and its wide application in various industrial sectors. The steel studied was supplied in the industrial homogenized condition, i.e., annealing after hot rolling and cooling in water. In turn, the study or evaluation of the mechanical behavior resulting from the application of two mechanisms of embrittlement (aging and hydrogen) simultaneously were not approached intensively in the literature, on the contrary, just a few references [17-19] was found by the present authors focusing in this subject.

\section{Materials and methods}

The material used in this study was a DSS 2205 type, received with a thickness of $4.13 \mathrm{~mm}$, hot rolled by a Steckel type mill and subjected to an annealing heat treatment at $1050^{\circ} \mathrm{C}$ for $300 \mathrm{~s}$ by the steel-plant. The steel composition was in accordance with Table 1 . The samples were then cold rolled in a laboratory mill at room temperature at a speed of $6.25 \mathrm{~m} \cdot \mathrm{min}^{-1}$. A $60 \%$ reduction in thickness was achieved after 9 passes, reaching a final thickness of $1.64 \mathrm{~mm}$. The present DSS tends to form $\alpha^{\prime}$-martensite due to cold deformation. To ensure that the steel is free of $\alpha^{\prime}$-martensite, an annealing was performed at $1100^{\circ} \mathrm{C}$ for $2 \mathrm{~h}$. On the other hand, DSS has a strong propensity to the formation of deleterious phases, such as phase $\sigma, \chi$, carbides and nitrides. This formation takes place between 600 and $950^{\circ} \mathrm{C}$. The temperature range between 800 and $850^{\circ} \mathrm{C}$ has faster kinetics [7]. Therefore, another sample was subjected to annealing heat treatment (aging) at $850^{\circ} \mathrm{C}$ for $24 \mathrm{~h}$ after the cold rolling process.

\subsection{Electrochemical hydrogen charging procedure}

The introduction of hydrogen into the steel was carried out by electrochemical charging with an electrolytic solution of $0.5 \mathrm{M} \mathrm{H}_{2} \mathrm{SO}_{4}$ containing $1 \mathrm{~g} / \mathrm{L}$ of thiourea, performed at a constant current density of $0.8 \mathrm{~mA} / \mathrm{cm}^{2}$. Platinum sheets were used as an anode and samples as a cathode. The mechanical degradation induced by hydrogen was evaluated in tensile tests in samples without (air) and with hydrogen charging for $24 \mathrm{~h}$ with continuous hydrogen load during the tensile test (in situ) to avoid leakage. The tensile tests were performed at room temperature in both samples, charged with hydrogen and uncharged with a slow strain rate, at a constant crosshead displacement speed of $0.6 \mathrm{~mm} / \mathrm{min}$, which corresponds to a strain rate of $1 \times 10^{-3} \mathrm{~s}^{-1}[15]$. The uncharged tensile test was carried out in the air, which was compared with the charged sample with continuous hydrogen charging during the test. The total hydrogen content charged into the DSS strip was determined after different times. This was following by the melting of small rectangles $(6 \mathrm{~mm} \times 8 \mathrm{~mm})$ at $1,550^{\circ} \mathrm{C}$ in a Galileo G8 set-up operated with an impulse furnace for heating and a thermal conductivity detector (TCD) for hydrogen detection. Since hydrogen is trapped in lattice defects, heating must be involved to release these atoms, so TDS was used. TDS can provide all the information obtained from the various methods, including the density, type and binding energy of a series of trap sites present in a material. Furthermore, the TDS technique is advantageous when applied to metals or crystallographic phases with a small diffusion coefficient for hydrogen atoms, such as the DSS. TDS experiments will reveal the hydrogen trap sites and classify them both qualitatively and quantitatively into strong and weak traps $[12,20,21]$.

\subsection{Microstructural characterization}

The microstructure was characterized using a scanning electron microscope (SEM) with electron backscatter diffraction (EBSD) and transmission electron microscope (TEM). The samples were prepared according to the standard metallography procedure with successive grounding and polishing and chemically etching with Beraha etchant. The final polishing with colloidal silica $0.04 \mu \mathrm{m}$ was used for examination and analysis in SEM with the EBSD technique. A W-filament SEM was used with an acceleration voltage of $20 \mathrm{kV}$ and a probe diameter of $200 \mathrm{~nm}$. The sample was tilted at an angle of $70^{\circ}$ and scanning with a $0.1 \mu \mathrm{m}$ step with image formation on a hexagonal grid. The OIM ${ }^{\mathrm{TM}}$ (Orientation Imaging Microscopy) software was used to collect and analyze EBSD patterns. The SEM was also used

Table 1. Chemical composition of duplex stainless steel 2205

\begin{tabular}{cccccccccc}
\hline Element & $\mathbf{C}$ & $\mathbf{M n}$ & $\mathbf{S i}$ & $\mathbf{C r}$ & $\mathbf{N i}$ & $\mathbf{P}$ & $\mathbf{S}$ & $\mathbf{M o}$ & $\mathbf{C u}$ \\
\hline Weight $\%$ & 0.013 & 1.81 & 0.38 & 22.45 & 5.31 & 0.02 & 0.0005 & 2.63 & 0.24 \\
\hline
\end{tabular}


for the recognition of the fracture surface characteristics to determine the mechanism of crack propagation.

Figure 1 shows the tensile specimen dimensions and scheme used to withdraw the sections for micrographs of the DSS 2205 cold rolled with $60 \%$ and aged at $850^{\circ} \mathrm{C}$ for $24 \mathrm{~h}$ and annealing for $2 \mathrm{~h}$ at $1100^{\circ} \mathrm{C}$.

Thin foils were prepared for analysis by TEM by electropolishing jet in $5 \% \mathrm{HClO}_{4}$ solution (perchloric acid) and $95 \%$ methanol at a temperature of approximately $-30^{\circ} \mathrm{C}$ using a voltage of $20 \mathrm{~V}$. The thin foils were examined using a FEI transmission electron microscope, Tecnai G2-20 system, operated at $200 \mathrm{kV}$. The X-ray diffraction was used for the identification and quantification of the phases volume fraction. This was performed in a Panalytical Empyrean diffractometer using a copper radiation $(\lambda=1,5406 \AA$ ) with a step size of $0.02^{\circ}$ for $1 \mathrm{~s}$ and an angular range, $2 \theta$, of $10-120^{\circ}$.

\section{Results and discussion}

Figure 2 a shows the microstructure of the DSS 2205 cold rolled with $60 \%$ thickness. Figure $2 \mathrm{~b}$ illustrates the

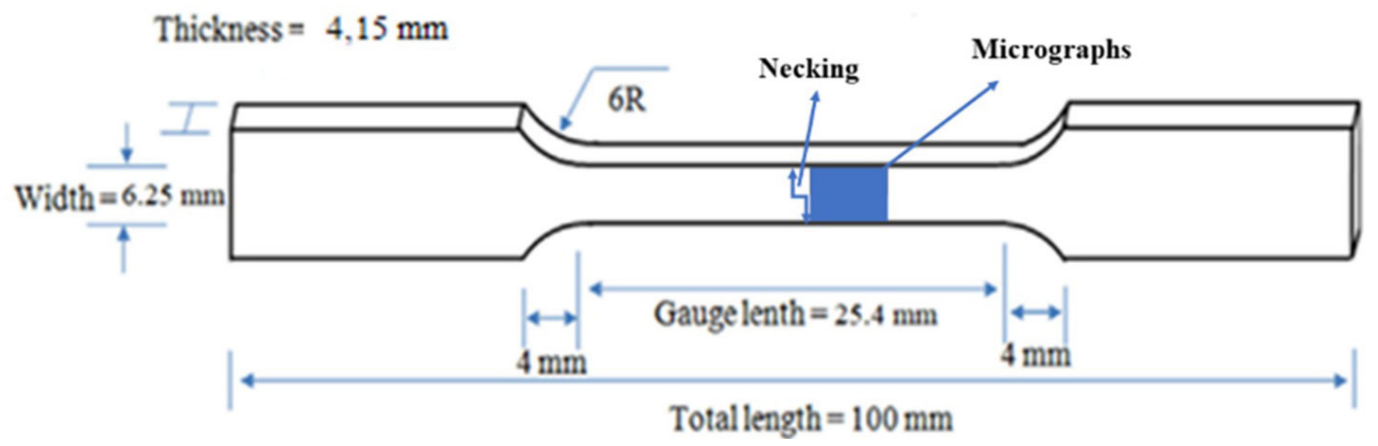

Figure 1. Tensile specimen dimensions and scheme used to withdraw the sections for micrographs of the DSS 2205 cold rolled with $60 \%$ and aged at $850^{\circ} \mathrm{C}$ for $24 \mathrm{~h}$ and annealing for $2 \mathrm{~h}$ at $1100^{\circ} \mathrm{C}$.
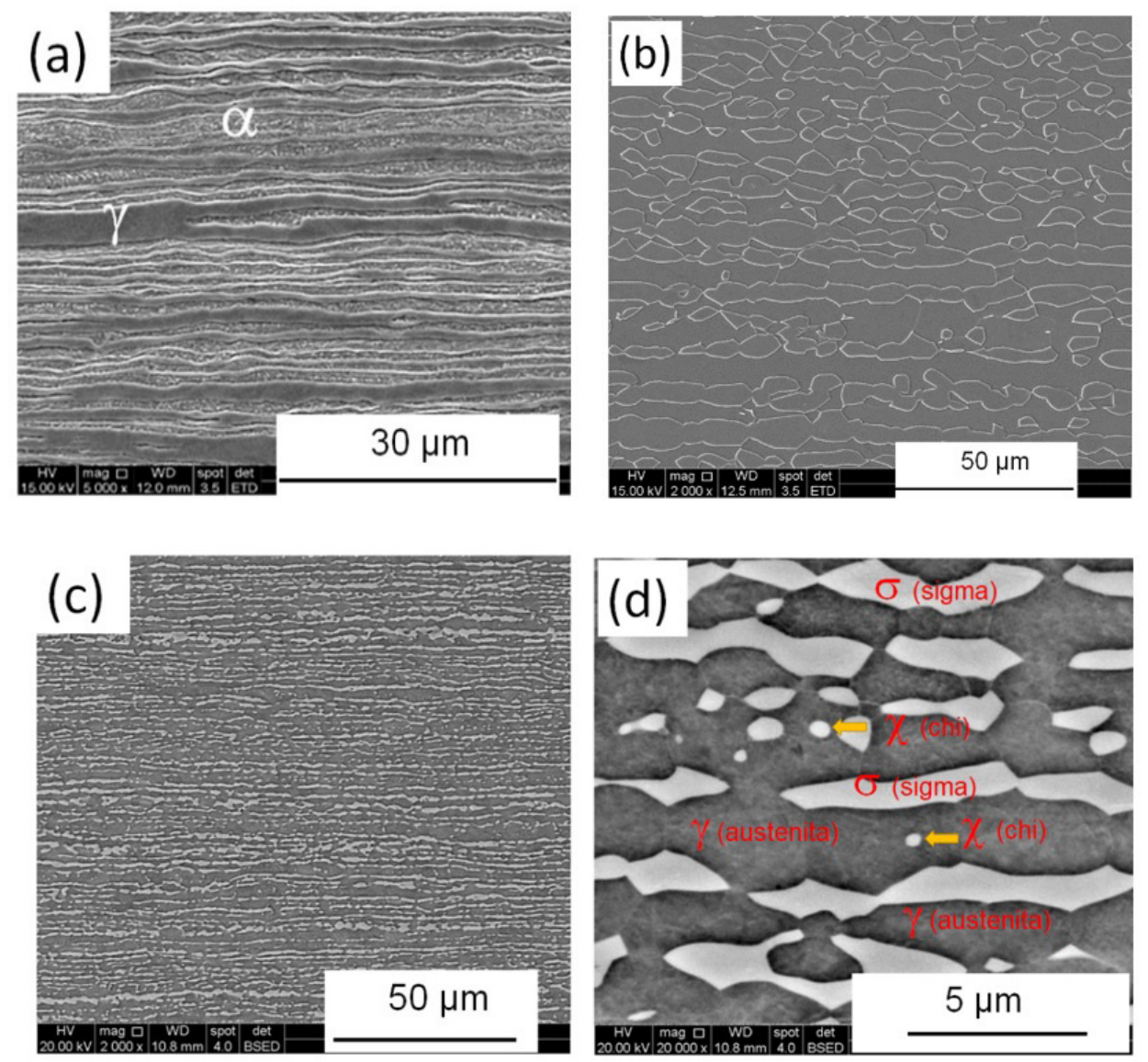

Figure 2. SEM micrograph of the (a) cold rolled DSS 2205 sample with $60 \%$ thickness reduction; (b) SEM micrograph of the DSS 2205 cold rolled with $60 \%$ and annealed at $1100^{\circ} \mathrm{C}$ for $2 \mathrm{~h}$; and (c,d) aged at $850^{\circ} \mathrm{C}$ for $24 \mathrm{~h}$. Etchant Beraha. 
micrograph of the sample annealed at $1100^{\circ} \mathrm{C}$ for $2 \mathrm{~h}$ after cold rolling. Figure $2 \mathrm{c}, \mathrm{d}$ illustrates the microstructure of the DSS 2205 cold rolled and aged at $850^{\circ} \mathrm{C}$ for $24 \mathrm{~h}$. Figure $2 \mathrm{~d}$ shows details of the austenite, $\sigma$ and $\chi$ phases. The matrix consists of the $\gamma$ phase, dark gray coloration, $\sigma$ phase, light coloration and $\chi$ phase, totally white regions. The grains intercalated between sigma and austenite, elongated in the direction of rolling are a characteristic of the duplex stainless steels. Figure 3a illustrates the microstructure of the DSS 2205 cold rolled $60 \%$ and aged at $850^{\circ} \mathrm{C}$ for $24 \mathrm{~h}$ obtained by TEM, as well as the electron diffraction pattern, Figure $3 b$.

Figure 3 a shows an annealing twin inside the austenite. Figure 4a illustrates several microcracks crossing the sigma phase until reaching the $\gamma$ phase, which is indicated by the arrow. Figure $4 \mathrm{~b}$, on the contrary, does not show any microcracks. Some features inside the austenite grains correspond to the formation of the strain induced martensite due to stress applied by the tensile test.

The measurement of the volume fraction of the phases was made by $\mathrm{x}$-ray diffraction, shown in Figure $5 \mathrm{a}, \mathrm{b}$. For cold rolled sample there is the proportion of $48 \%$ of $\gamma$ and
$52 \%$ of $\alpha$, along with strain induced martensite, $\alpha^{\prime}$, that appear at same peaks of ferrite, Figure 5a and Figure $4 \mathrm{~b}$. Figure $5 \mathrm{~b}$ shows the diffractogram of the aged sample. After the aging, there was the onset of deleterious phases $(\sigma, \chi$ and carbide) [8-10]. The volume fraction of each phase was calculated by X-ray diffraction, using the method of integration of the main peaks, as well as by EBSD. These results can be compared in Table 2. The differences are due to the resolution of the phase $\sigma$ and $\alpha$, and not the inclusion of carbide and nitride in the EBSD technique, Figure 6a-g. The results presented in the diffractogram in Figure 5a,b show a microstructure with a volume fraction ratio close to $50 / 50 \%$. The same result was obtained for the sample annealed at $1100^{\circ} \mathrm{C}$ for $2 \mathrm{~h}[15], 50.0 \pm 1.5 \%$, which is the optimum condition for the steel properties.

In Figure 7 the contents of hydrogen (wppm) are plotted according to the heating treatment and time, TDS spectrum after charging of hydrogen up to $24 \mathrm{~h}$ in samples of DSS 2205 cold rolled with $60 \%$ reduction, aged for $24 \mathrm{~h}$ at $850^{\circ} \mathrm{C}$, and annealing at $1100^{\circ} \mathrm{C}$ for $2 \mathrm{~h}$. The TDS works effectively for the identification of different encapsulation
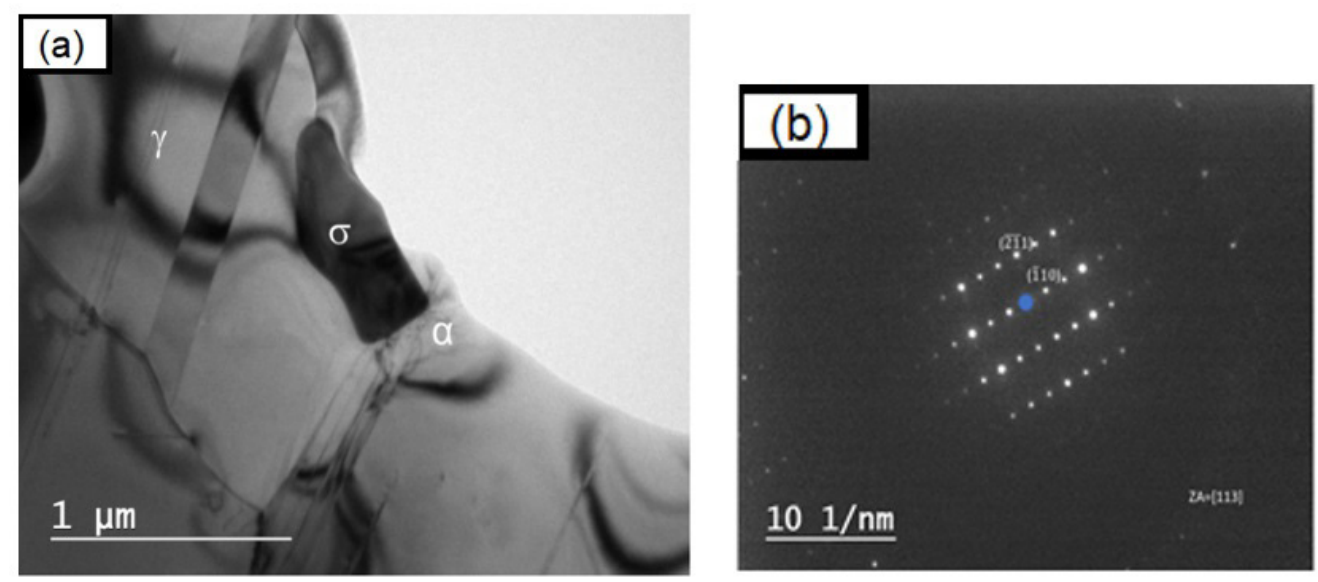

Figure 3. (a) Image obtained from the bright-field TEM made in the rolling plane of the DSS 2205 cold rolled $60 \%$ and aged for $24 \mathrm{~h}$ at $850{ }^{\circ} \mathrm{C}$; (b) Selected area electron diffraction of the $\sigma$ phase in (a).
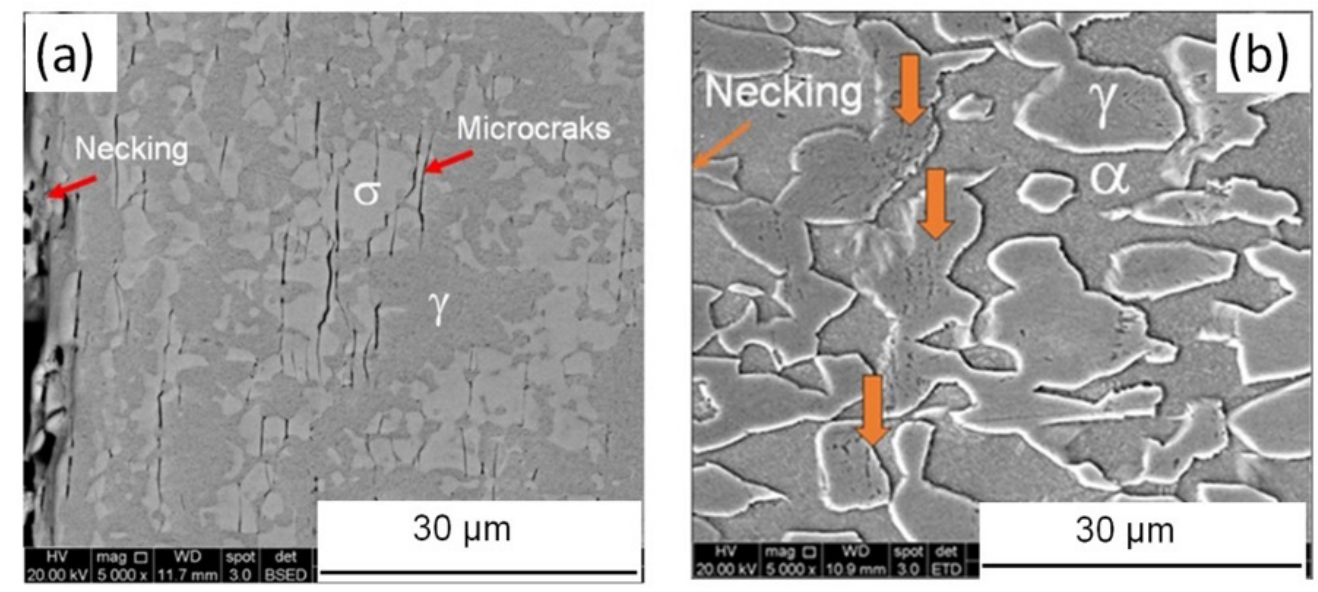

Figure 4. Micrographs obtained using SEM made in the rolling plane near the necking region (Figure 1) of the (a) DSS 2205 cold rolled $60 \%$ and aged for $24 \mathrm{~h}$ at $850^{\circ} \mathrm{C}$; (b) aged for $2 \mathrm{~h}$ at $1100^{\circ} \mathrm{C}$. Observe the difference in grain size between the samples and strain induced martensite, ((b), arrows). 
(a)

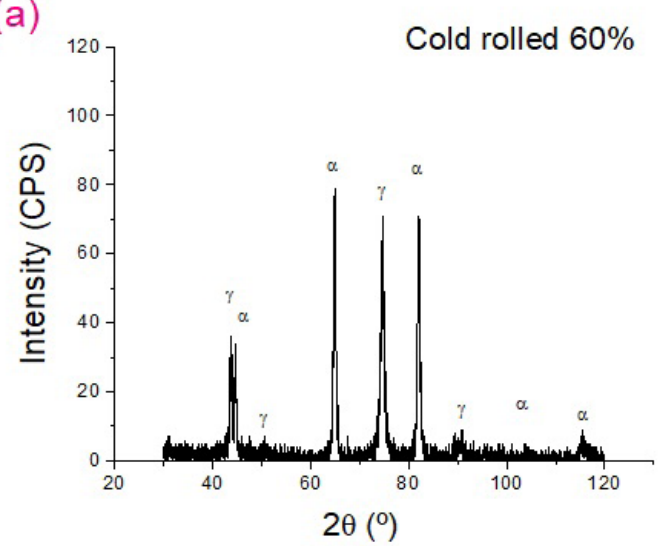

(b)

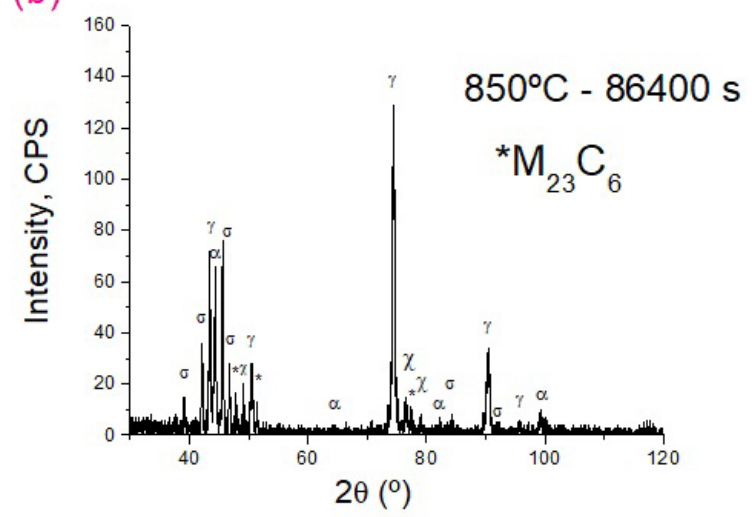

Figure 5. DSS 2205 diffractogram of (a) cold rolled sample with $60 \%$ reduction; and (b) aged for $24 \mathrm{~h}$ at $850^{\circ} \mathrm{C}$.

(a)

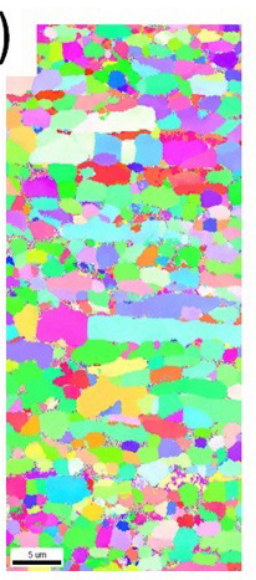

(d)

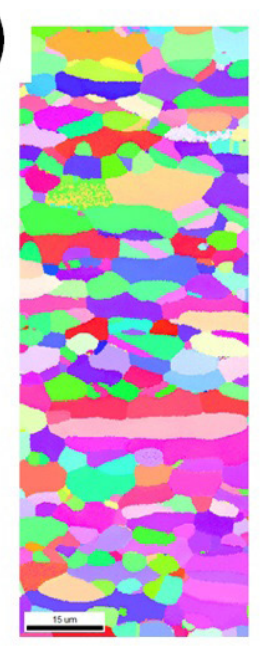

(b)

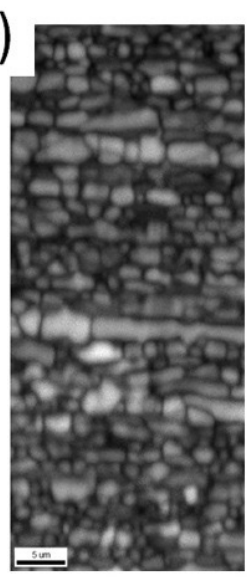

(e)

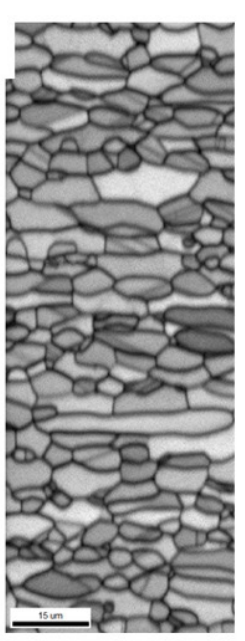

(c)

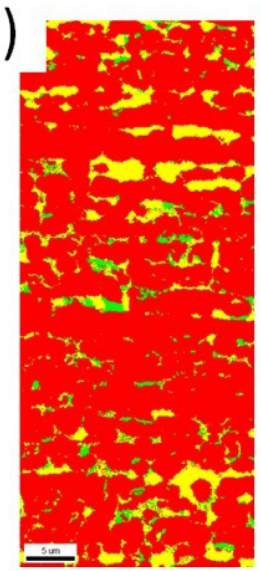

(f)

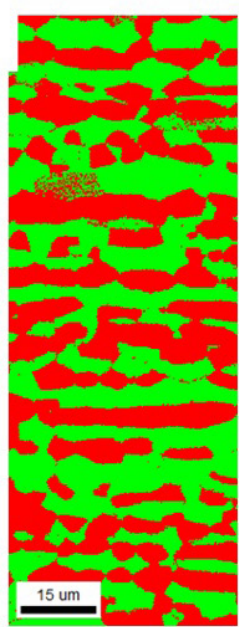

\begin{tabular}{|c|c|c|}
\hline \multicolumn{3}{|c|}{ Color Coded Map Type: Phase } \\
\hline & Total & Partition \\
\hline Phase & Fraction & Fraction \\
\hline Ferrite & 0.506 & 0.506 \\
\hline Austenite & 0.494 & 0.494 \\
\hline
\end{tabular}

Boundarles: <none>

Figure 6. (a) Images obtained from EBSD made in the thickness plan of the DSS 2205 sample (a-c) cold rolled and aged for $24 \mathrm{~h}$ at $850^{\circ} \mathrm{C}$. (a) Inverse pole figure map; (b) quality index; (c) phase map. In (d-f) the same series for sample cold rolled and annealed at $1100^{\circ} \mathrm{C}$ for $2 \mathrm{~h}$. 
sites and for the measurement of energy and density linked to these sites [20,21]. When hydrogen is charged to metals under identical charging conditions, it gets stuck in various network defects depending on their densities and binding energies. Consequently, the amount of hydrogen tracer and hydrogen desorption temperatures measured using TDS correlate with the nature of trap sites such as lattice defects and the bonding energies between hydrogen and trapping sites, respectively [20,21]. The amount of hydrogen absorbed in the steel during the charging, not only depends on the hydrogen charging current, density and temperature, but also depends on the hydrogen diffusion [12]. It was shown, using Lee model, that the trapping phenomenon in lean duplex stainless steel, LDS, and super duplex stainless, SDSS, can be classified as reversible traps $(<60 \mathrm{~kJ} / \mathrm{mol})$; trapping sites were identified and attributed to elastic stress field of dislocation [0-20 kJ/mol], screw's dislocation core or grain boundaries $(20-30 \mathrm{~kJ} / \mathrm{mol})$, and at higher activation energies high angle boundaries, vacancy, austenite-ferrite interface $(40-50 \mathrm{~kJ} / \mathrm{mol}$, and clusters, $60 \mathrm{~kJ} / \mathrm{mol})[12,22]$. Figure 8 describes the influence of the charging time on the concentration of hydrogen for samples of DSS 2205 cold rolled and annealed at $1100^{\circ} \mathrm{C}$ for $2 \mathrm{~h}$ and at $850^{\circ} \mathrm{C}$ for $24 \mathrm{~h}$.

An analysis of the complete release (desorption) allows the diffusible hydrogen dissolved in the steel matrix and the trapped to be differentiated. The trapped hydrogen consisted mainly of that dissolved in the austenite phase and interfaces (grain boundary and precipitated phases-matrix) [17]. With the results obtained by TDS measurement, it is observed a lower hydrogen release in the aged material compared to the annealed state, which was already expected by the low amount of ferrite, Table 2. But it can also be analyzed that there was no alteration in the peak of hydrogen release, showing that the presence of the sigma phase has little interference with the traps of hydrogen in the steel.

The annealed sample contains more hydrogen compared to the aged sample. This fact is linked to the amount of ferrite achieved for $24 \mathrm{~h}$ of aging. The aged DSS contains more austenite, volume fraction, $\mathrm{Vv}=60 \%$, but much less ferrite, $\mathrm{Vv}_{\mathrm{v}}=14 \%$, Table 2, compared to the annealed steel at high temperature, $1100^{\circ} \mathrm{C}$ for $2 \mathrm{~h}$ $(\mathrm{Vv}=50 \%[15]$,$) . The diffusion of hydrogen is slower in$ austenite, it signs a lower charge of hydrogen. In addition, diffusion is faster in ferrite [12,19-21]. In the aged sample, the ferrite transforms largely for the sigma phase [7-9], reducing the hydrogen paths.

The diffusion coefficient decreases in the aged DSS with the sigma phase [19]. Hydrogen trapping in DSS is dominated by reversible traps such as the strain regions around the dislocations cores with an activation energy of approximately $20-40 \mathrm{~kJ} / \mathrm{mol}$, vacancies and

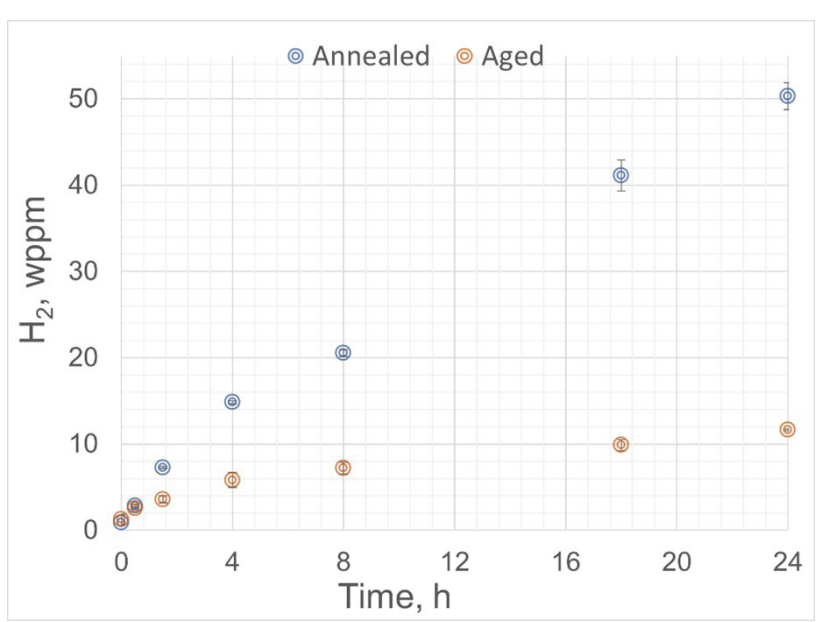

Figure 7. Influence of the charging time on the concentration of hydrogen for samples of DSS 2205 cold rolled with $60 \%$ and annealed at $1100^{\circ} \mathrm{C}$ for $2 \mathrm{~h}$, and at $850^{\circ} \mathrm{C}$ for $24 \mathrm{~h}$.

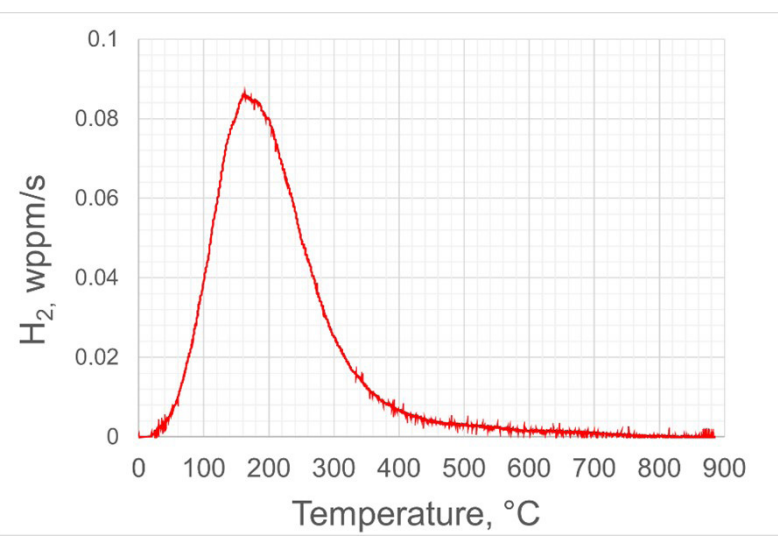

Figure 8. Hydrogen content (wppm) as a function of heating temperature (TDS spectrum) after hydrogen charging for $24 \mathrm{~h}$ in cold rolled 2205 DSS samples with $60 \%$ reduction and annealed at $1100^{\circ} \mathrm{C}$ for $2 \mathrm{~h}$ and $850^{\circ} \mathrm{C}$ for $24 \mathrm{~h}$.

Table 2. The phases volume fraction of the steel aged at $850^{\circ} \mathrm{C}$ for $24 \mathrm{~h}$

\begin{tabular}{lcc}
\hline \multicolumn{1}{c}{ Phases } & XRD (\%) & EBSD (\%) \\
\hline Austenite & 59.9 & 83.3 \\
Ferrite & 13.6 & 4.3 \\
Sigma & 21.5 & 12.4 \\
$\mathrm{M}_{23} \mathrm{C}_{6}+\chi$ & $\sim 5.0$ & - \\
Total & 100 & 100 \\
\hline
\end{tabular}

$\gamma$ - $\alpha$ interfaces $(50-57 \mathrm{~kJ} / \mathrm{mol})[12,21,22]$. However, for Vaňová P. and Sojka J [19]. the sigma phase acts as an irreversible hydrogen trap and decreases the effective hydrogen coefficient.

The aging steel embrittlement appeared already in consequence of phase sigma precipitation and therefore the influence of hydrogen was minor [19].

The melt extraction revealed a hydrogen content in the microstructure of up to $50 \mathrm{wppm}$ for annealed 
condition, while for the aged sample it was 10 wppm. The TDS spectra indicate that hydrogen was dissolved interstitially in the austenite and ferrite phases. The peak height increased with increasing hydrogen concentration.

Hydrogen behaviour in SAF2507, super DSS, and SAF2205, standard DSS, was investigated employing internal friction measurement [18]. The internal friction measurements were conducted over a temperature range from $77 \mathrm{~K}$ to $773 \mathrm{~K}$ using an inverted torsion pendulum for a frequency of $1.5 \mathrm{~Hz}$ after the specimens were heated at $1223 \mathrm{~K}$ for various times. $\sigma$ phase precipitated in the ferrite and the ferrite/austenite interface. A significant peak appeared at $245 \mathrm{~K}$ after the hydrogen charging of the super DSS and standard DSS [18]. The peak was associated with hydrogen in austenite in the reversible sites. As the specimens were heated at $1223 \mathrm{~K}$ for various times, the sigma phase consisting of $\mathrm{Fe}-\mathrm{Cr}$ compound precipitated in the ferrite and the ferrite/austenite interface. The broadening of the internal friction peak at $245 \mathrm{~K}$ and scattering of the internal friction value took place after hydrogen charging for the sigma phase precipitation. Overlapping of two peaks was associated with hydrogen in austenite and the peak associated with hydrogen in sigma phase was observed. The precipitation of sigma phase caused suppression of hydrogen diffusion in super DSS [18]. According to geometric calculations of the crystal structure of the sigma phase, hydrogen atoms easily move into tetragonal sites of the sigma phase lattice [18].

The results of the tensile tests can be observed in Figure 9. No variation of the properties between the two conditions was observed, given the steel without hydrogen already being fragile due to the precipitation of the deleterious phases. The yield strength did not change significantly between samples with the absence or presence of hydrogen. On the other side, the tensile strength decreased about $150 \mathrm{MPa}$ with an increasing amount of initial hydrogen, as related by Iacoviello using

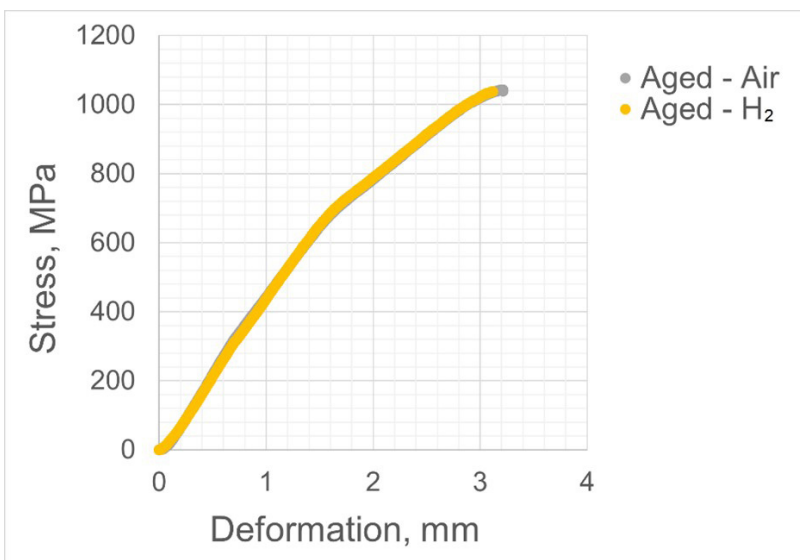

Figure 9. Stress-strain tensile curves for cold rolling with $60 \%$ reduction, followed by aging at $850^{\circ} \mathrm{C}$ for $24 \mathrm{~h}$ and after charging with hydrogen. a Z2CND2205 aged DSS [17]. The hydrogen charged sample exhibited limited ductility. It was observed that the susceptibility to HE causes premature intergranular branched may lead to low ductility and low toughness of the material [18].

To acquire more information about the fracture mechanisms, the fracture surfaces of the aged sample and that aged and charged with hydrogen were analyzed in SEM.

The appearance of the fracture is characterized by an intergranular feature, with a small size of these microvoids (grain boundaries walls). This is due to the ultrafine grain size produced in the cold rolling and annealing process (aging) at low temperature $\left(850^{\circ} \mathrm{C}\right)$, compare Figure $6 \mathrm{~b}$ and $6 \mathrm{f}$. The intergranular characteristic is due to the presence of deleterious phases, typically $\sigma$ and $\chi$ phases. The presence of these phases and carbides was confirmed by $x$-ray diffraction analyses, Figures $5 b$ and $6 c$.

In Figure 10a,b the surface of the hydrogen-free fracture is characterized by intergranular aspects. In Figure 11a,b the surface of the sample with hydrogen charging is characterized also by the same features, but their size is smaller than the sample fractured in the air $[23,24]$. On the fracture surface of the tensile specimen without charging with hydrogen, Figure $10 \mathrm{~b}$, it is noted a more irregular appearance with the formation of steps, comparing it with the fracture of the material charged, shown in Figure 11b, a smoother surface.

The sigma phase precipitation affected the notch tensile strength, and hydrogen embrittlement of 2507 DSS, occurred more than 2205. Fracture morphology of the hydrogen embrittlement was related to the morphology of austenite with sigma.

The unit facet size was much smaller than without sigma phase. A lot of sigma phase was observed on the fracture surface, Figures 10 and 11. The facet size is much smaller than that of non-sigma specimens [18]. The amount of sigma phase was $21 \% \mathrm{Vv}$ (Table 2) in the microstructure. The sigma phase precipitated from the ferrite with the formation of secondary austenite. Consequently, the fracture morphology of hydrogen embrittlement is related to the morphology of $\sigma$, because the sigma phase precipitated together with austenite, $\gamma 2$.

Subsequently, cracks are expected to start in the region where vacant-type defects are at a critical concentration because of (a) nanovoids nucleation and coalescence or (b) network instability [22,23]. A possible explanation for this difference is the concentration of hydrogen in the interface of the sigma-austenite phases that assist the fragile rupture of steel [17]. Secondary microcracks and many particles of the sigma phase on the grain boundaries walls can be seen in Figure 10c, with less intensity in Figure 11c. The results demonstrate that longer the hydrogen charging time, the greater depth of the embrittlement zone. Both samples exhibited a limited amount of post-uniform elongation. 

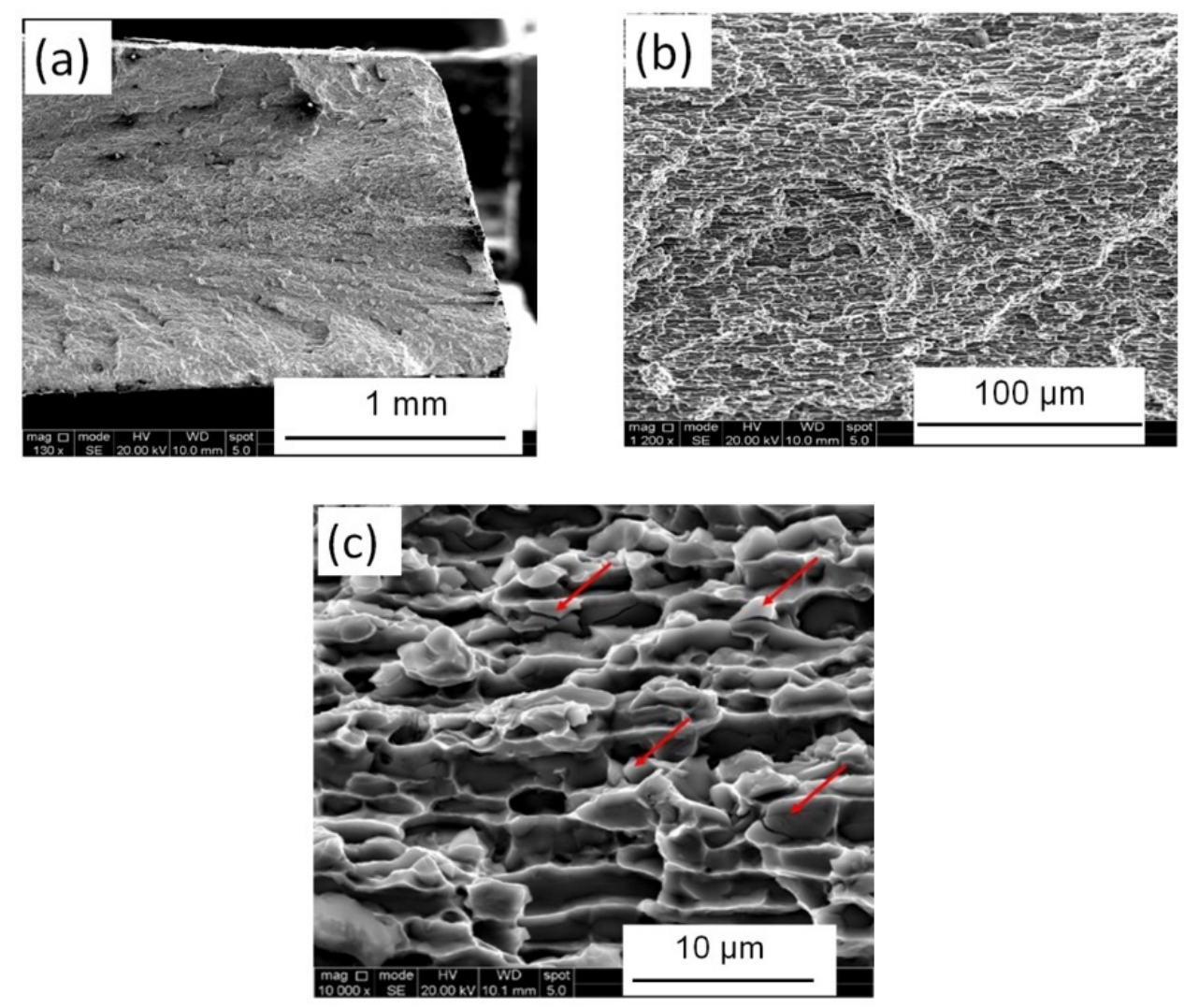

Figure 10. (a) SEM images show the fracture surface in the electrochemical hydrogen charged specimen. (b,c) show the morphology of the microvoids and sigma particles in detail (red arrows).
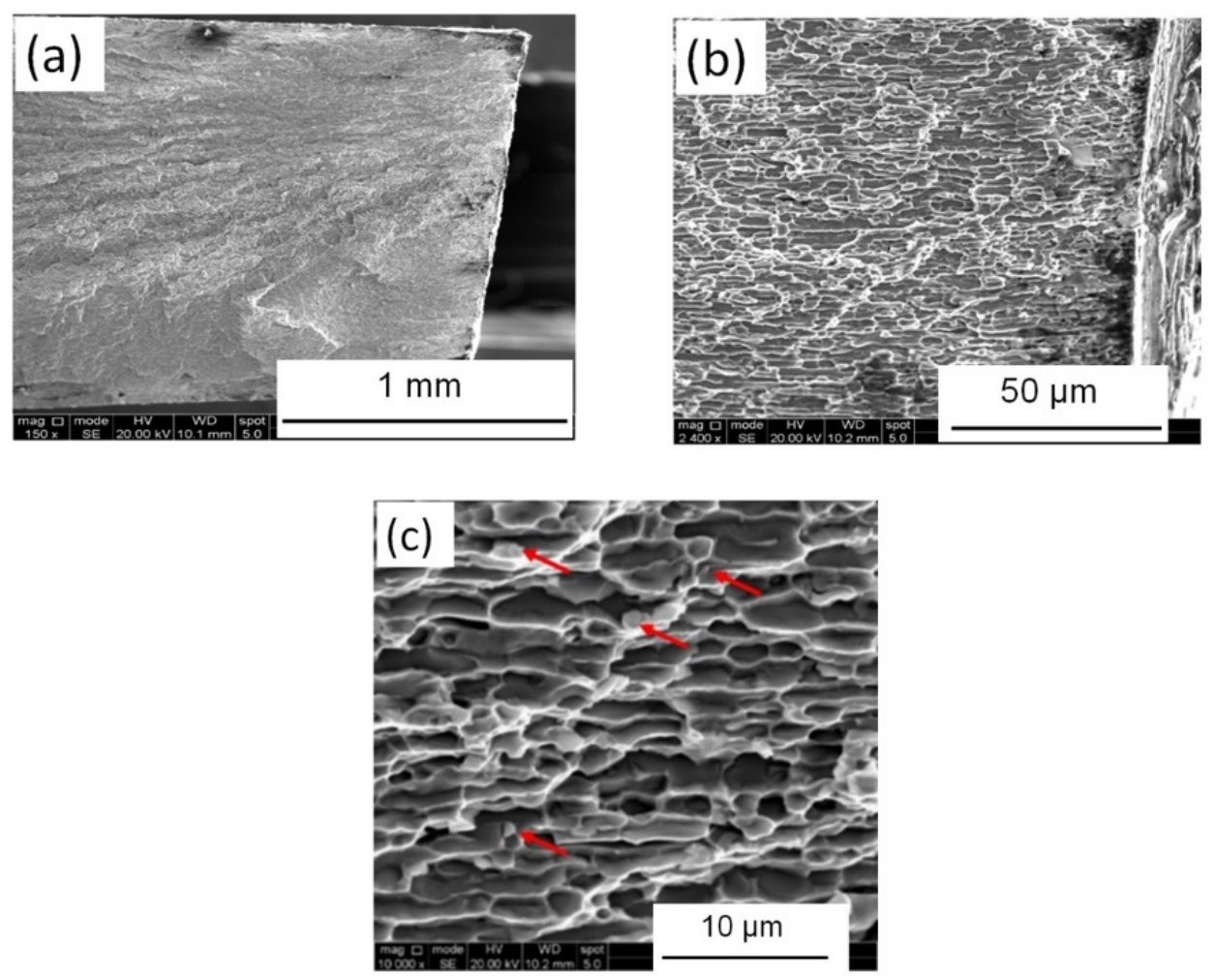

Figure 11. (a) SEM images show the fracture surface in the electrochemical hydrogen charged specimen. (b,c) show the morphology of the microvoids and sigma particles in detail (red arrows). 


\section{Conclusions}

Sample of the DSS 2205 cold rolled and aged at $850^{\circ} \mathrm{C}$ for $24 \mathrm{~h}$ was subjected to charging with hydrogen. In the aged condition, the deleterious phases were identified, $\sigma, \chi$ and carbide $\left(\mathrm{M}_{23} \mathrm{C}_{6}\right)$. A relationship between the embrittlement of 2205 duplex stainless steel and hydrogen charging conditions was established by further analysis of fracture surface morphology.

Tensile tests in situ of hydrogen charged sample demonstrated a considerable loss of ductility, both in the aged sample and in the sample aged and charging with hydrogen, reaching about $5 \%$ of total elongation, but high tensile strength, over $1000 \mathrm{MPa}$. A mixture of ductile fracture indicated by microvoids (dimples) and intergranular character was observed. The charged sample surface exhibits very shallow and smooth dimples. Almost all areas of the fracture surface consisted of dimples-intergranular patterns, but several $\sigma$ particles contain microcracks. Hydrogen enhanced the localization of shear deformation, which subsequently accelerated the nucleation of microvoids and the formation of void sheets thereby reducing their average size.

No hydrogen charging fracture surface also have characteristics of intergranular. For the sample charged a hydrogen-induced fracture shows a similar appearance, but with small microvoids. By SEM examination, it was possible to show that fracture cracks appear initially in the sigma phase, and continue propagating through the austenite phase, since there is only a small volume fraction of ferrite.

The melt extraction revealed a hydrogen content in the steel of up to $50 \mathrm{wppm}$ for annealed condition, while for the aged sample it was $10 \mathrm{wppm}$. The TDS spectra indicate that hydrogen was dissolved interstitially in the austenite and ferrite phases as a reversible site. It was possible that $\sigma$ phase contains some interstitials hydrogen atoms.

\section{Acknowledgements}

The authors thank CAPES-PROEX, FAPEMIG, and CNPq for the research grants made available to students and financial support. The authors also acknowledge the support of the FWO SB PhD fellow of L. Clays grant n. 1S16618N, and the Special Research Fund (BOF) of the University of Ghent referring to the equipment used (concession BOF15/ BAS/062) and a post-doctoral fellowship FWO (grant BOF01P03516). Acknowledgements are expressed to the UFMG Microscopy Center for providing scientific support. We also thank the company Aperam South America S/A for supplying samples of DSS.

\section{References}

1 Gunn R. Duplex stainless steels: microstructure, properties and applications. 1st ed. Cambridge: Abington Publishing; 1997.

2 Fargas G, Akdut N, Anglada M, Mateo A. Microstructural evolution during Industrial Rolling of a Duplex. ISIJ International. 2008;48:1596-1602.

3 Lo KH, Shek CH, Lai JKL. Recent developments in stainless steels. Materials Science Engineering E. 2009;65:39104.

4 Alvarez-Armas I. Duplex stainless steels: brief history and some recent alloys. Recent Patents on Mechanical Engineering. 2008;1:51-57.

5 Djaziri S, Li Y, Nematollahi GA, Grabowski B, Goto S, Kirchlechner C, et al. A new paradigm for exceptional steels. Advanced Materials. 2016;28:7753-7757.

6 Rosso M, Peter I, Suani D. About heat treatment and properties of duplex stainless steels. Journal Achievements Materials Manufacturing Engineering. 2013;59:26-36.

7 Hsieh C-C, Wu W. Overview of intermetallic sigma phase precipitation in stainless steels. ISRN Metallurgy. 2012;66:1-16.

8 Llorca-Isern N, López-Luque H, López-Jiménez I, Biezma MV. Identification of sigma and chi phases in duplex stainless steels. Materials Characterization. 2016;112:20-29.

9 Calliari I, Zanesco M, Ramous E. Influence of isothermal aging on secondary phases precipitation and toughness of duplex stainless steel SAF 2205. Journal of Materials Science. 2006;41:7643-7649.

10 Hosseini VA, Karlsson L, Wiesmann S, Fuertes N. Effect pf sigma phase morphology on the degradation of properties in a super duplex stainless steel. Materials (Basel). 2018;11:1-20. [MDPI]

11 Zheng W, Hardie D. The Effect of Hydrogen on the Fracture of a Commercial Duplex Stainless Steel. Corrosion Science. 1991;32:23-36.

12 Silverstein R, Sobol O, Boellinghaus T, Unger W, Eliezer D. Hydrogen behavior in SAF 2205 duplex stainless steel. Journal of Alloys and Compounds. 2017;695:2689-2695. 
13 Silva BRS, Salvio F, Santos DS. Hydrogen induced stress cracking in UNS S32750 super duplex stainless steel tube weld joint. International Journal of Hydrogen Energy. 2015;40:17091-17101.

14 Robertson IM, Sofronis P, Nagao A, Martin ML, Wang S, Gross D, et al. Hydrogen Embrittlement Understood. Metallurgical and Materials Transactions. A, Physical Metallurgy and Materials Science. 2015;46:2323-2341.

15 Maria GGB, Claeys L, Depover T, Santos DB, Verbeken K. The Hydrogen Induced Mechanical Degradation of Duplex Stainless Steel. Steel Research International. 2019;90:1-6.

16 Luo H, Dong CF, Liu ZY, Maha MT, Li G. Characterization of hydrogen charging of 2205 duplex stainless steel and its correlation with hydrogen-induced cracking. Materials and Corrosion. 2013;64:26-33.

17 Iacoviello F, Habashi M, Avallini M. Hydrogen embrittlement in the duplex stainless steel Z2CND2205 hydrogencharged at $200^{\circ}$ C. Materials Science and Engineering A. 1997;224:116-124.

18 Kuroda T. Role of sigma phase on hydrogen embrittlement of super duplex stainless steels. Transactions of JWRI. 2005;34(2):63-68.

19 Vaňová P, Sojka J. Hydrogen embrittlement of duplex steel tested using slow strain rate test. Metalurgija. 2014;53(2):163-166.

20 Escobar DP, Verbeken K, Duprez L, Verhaghe M. Evaluation of hydrogen trapping in high strength steels by thermal desorption spectroscopy. Materials Science and Engineering A. 2012;551:50-58.

21 Claeys L, Cnockaert V, Depover T, De Graeve I, Verbeken K. Critical assessment of the evaluation of thermal desorption spectroscopy data for duplex stainless steels: A combined experimental and numerical approach. Acta Materialia. 2020;186:190-198.

22 Dabah E, Lisitsyn V, Eliezer D. Performance of hydrogen trapping and phase transformation in hydrogenated duplex stainless steels. Materials Science and Engineering A. 2010;527:4851-4857.

23 Luu WC, Liu PW, Wu JK. Hydrogen transport and degradation of a commercial duplex stainless steel. Corrosion Science. 2002;44(8):1783-1791.

24 Matsuo T, Yamabe J, Matsuoka S. Effects of hydrogen on tensile properties and fracture surface morphologies of Type 316L stainless steel. International Journal of Hydrogen Energy. 2014;39:3542-3551.

Received: 17 Apr. 2020

Accepted: 2 Feb. 2021 